\title{
Childhood Pneumonia: Prevalence and Associated Factors as Seen at a Tertiary Health Institution in Southeast Nigeria
}

\author{
Chukwuemeka Ngozi Onyearugha, Nneka Chioma Okoronkwo* \\ Department of Paediatrics, Abia State University Teaching Hospital, Aba, Nigeria \\ Email address: \\ chukwuemekaonye@yahoo.com (C. N. Onyearugha), nnekaceo@rocketmail.com (N. C. Okoronkwo) \\ ${ }^{*}$ Corresponding author
}

\section{To cite this article:}

Chukwuemeka Ngozi Onyearugha, Nneka Chioma Okoronkwo. Childhood Pneumonia: Prevalence and Associated Factors as Seen at a Tertiary Health Institution in Southeast Nigeria. American Journal of Pediatrics. Vol. 7, No. 3, 2021, pp. 121-125.

doi: 10.11648/j.ajp.20210703.16

Received: June 25, 2021; Accepted: July 21, 2021; Published: July 24, 2021

\begin{abstract}
Background: Pneumonia has been reported to be a leading cause of mortality in children aged less than 5 years worldwide particularly in low resource nations. To achieve the Sustainable Developmental Goal (SDG) 3.2 which aims at reducing neonatal mortality and under five mortality, effective steps should be taken to stem the prevalence and mortality from childhood pneumonia. Aim: To determine the prevalence, monthly variations and mortality from pneumonia in children aged 1 month to 16 years at the department of Paediatrics of the Abia State University Teaching Hospital, Aba. Patients and methods: This was a retrospective review of the medical records of children aged 1 month to 16 years, diagnosed with pneumonia, at the department of Paediatrics of the Abia State University Teaching Hospital, Aba. Relevant information were extracted from case files of qualified subjects and subsequently analyzed using SPSS version 24. Result: There was a total of 440 admissions out of which 74 had a diagnosis of pneumonia, giving a prevalence of $16.8 \%$. Six of the cases had inadequate data and were discarded. Sixty eight (68) were used for subsequent analysis. Forty five (45) were males, while 23 were females, giving a male: female ratio of 1.8: 1 . Approximately $88 \%$ of the cases occurred in children aged $\leq 5$ years with $61.8 \%$ of the patients aged less than one year. The greatest monthly prevalence, 25\%; was in January and February. Mortality rate was $4.4 \%$. Conclusion: The prevalence of childhood pneumonia is high. Children below 5 years are very vulnerable. Effective steps to reduce childhood pneumonia will drastically reduce under-5 mortality and achieve SDG 3.2.
\end{abstract}

Keywords: Childhood Pneumonia, Prevalence, Mortality, Aba, Nigeria

\section{Introduction}

To achieve the Sustainable Developmental Goal (SDG) 3.2 which aims at reducing neonatal mortality and under five mortality to 12.5 and 25 per 1000 live births respectively by year 2030, effective steps should be taken to curb the prevalence of childhood pneumonia, a major cause of underfive mortality.

Childhood pneumonia has been reported as the highest cause of childhood mortality globally [1]. Pneumonia has also been noted as number one killer disease among children aged under five years [2]. Nigeria has the highest mortality from childhood pneumonia globally [3]. In 2018, pneumonia accounted for over 800,000 deaths of children aged under five globally, with Nigeria accounting for the highest mortality with 162,000 deaths or 443 deaths a day or 18 deaths per hour [3].

The aetiological agent implicated in childhood pneumonia varies with the age of the child. They include streptococcus pneumoniae, haemophilus influenzae type $\mathrm{B}$ and respiratory syncytial virus $[4,5]$. While respiratory syncytial virus is rife in younger children, streptococcus pneumoniae is the most common across all ages of childhood $[4,5]$.

Risk factors for the development of pneumonia in children include prematurity, younger age, malnutrition, lack of exclusive breast feeding, indoor air pollution, and overcrowding. Others [5] are vitamin A and zinc deficiency, outdoor air pollution, humidity, cold, disease conditions such as malaria, asthma, diarrhea, sickle cell disease, immunodeficiency states including HIV, malignancy states, immunosuppressive therapy $[6,7]$ amongst others.

Pneumonia could be diagnosed using the WHO case 
definition of cough, difficulty in breathing, fast breathing, and chest in drawing [8]. Additional criteria for severe disease warranting admission include danger signs of inability to take in orally, altered sensorium and seizures [8]. Diagnosis can also be made by laboratory and radiological investigations [9].

Pneumonia varies in prevalence in different parts of the world, different parts of a country and different communities depending on the climatic, socioeconomic, environmental, healthcare seeking behavior of care givers and availability of health care services. For instance, the prevalence of pneumonia is much lower in developed countries compared to developing countries. USA and UK documented a prevalence rates of 15.7-22.5/100,000 [10] and 14.4/10,000 [11] respectively. These figures are largely due to higher socioeconomic state, optimal sanitation and availability of quality healthcare services compared to less developed nations. Higher rates of pneumonia are obtained from developing nations with: $18.4 \%$ in Ghana [12], $51 \%$ in Bangladesh [13], 27.68\% in Makurdi [14], north central Nigeria, and $23.5 \%$ at Ilesha, southwest Nigeria [15].

Stemming the prevalence and mortality of childhood pneumonia goes a long way towards the attainment of SDG3.2 which aims at reduction of under-five mortality to at least 25 per 1000 live births by the year 2030 [16]. Curbing the prevalence and mortality of pneumonia begins with the determination of its prevalence and mortality, and documenting the associated factors in a community.

This study was therefore undertaken to determine the prevalence, mortality and related factors of childhood pneumonia among children presenting at the Abia State University Teaching Hospital, Aba. Such a study, to the best of knowledge of the authors, has never been undertaken in this centre previously. It is hoped that the result obtained will highlight the magnitude of the problem, provide a baseline data on the subject and serve as a veritable tool in the formulation of policies aimed at the prevention and effective management of childhood pneumonia in the community.

\section{Patients and Method}

This was a 12 months (January to December 2016) retrospective review of children aged 1 month to 16 years, admitted into the Department of Paediatrics of the Abia State University Teaching Hospital (ABSUTH) Aba, Southeast Nigeria. The academic hospital serves as a tertiary health care institution and referral centre for peripheral hospitals in Aba and neighboring states.

The Department of Paediatrics is manned by 6 consultants, 12 registrars and 10 house officers (who do 3 months rotation before proceeding to other departments). All cases of admission were reviewed by at least the registrar on call before commencement of further management. Diagnosis was made on patients based on clinical features and laboratory results.

All the case records of children admitted into Children Emergency Ward and Children Medical Ward, with the diagnosis of pneumonia, within the study period, were retrieved from the Medical Records Department of ABSUTH.
Relevant information including age, gender, diagnosis, month of illness, duration and outcome of admission were extracted and documented on excel.

Exclusion criteria were neonates, those aged more than 16 years and those with inadequate data.

Ethical clearance was obtained from the Ethics Committee of ABSUTH before the commencement of the study.

The data were analyzed using SPSS ((Statistical Package for the Social Sciences) software, version 24.0. The frequency tables were generated for all major variables of interest. Chi-square test was used to test for the significance of association between pneumonia and other variables. A confidence interval of $95 \%$ was used, and for all analyses, $\mathrm{p}<0.05$ was taken as statistically significant.

\section{Results}

There was a total of 440 admissions out of which 74 had a diagnosis of pneumonia, giving a prevalence of $16.8 \%$. Six of the cases had inadequate data and were discarded. Sixty eight (68) were used for subsequent analysis. There were 45 males and 23 females giving a male: female ratio of 1.8: 1 . Table 1 shows the gender distribution of patients, while table 2 shows the distribution of patients by age.

Table 1. Gender distribution of patients.

\begin{tabular}{lll}
\hline Gender & Frequency & Percentage \\
\hline Male & 45 & 66.2 \\
Female & 23 & 33.8 \\
Total & 68 & 100.0 \\
\hline
\end{tabular}

$88.3 \%$ of the cases occurred in children aged $\leq 5$ years with $42(61.8 \%)$ aged less than one. Other details are in table 2 below.

Table 2. Distribution of patients by age.

\begin{tabular}{lll}
\hline Age (years) & Frequency & Percentage \\
\hline$<1$ & 42 & 61.8 \\
$1-5$ & 18 & 26.5 \\
$>5$ & 8 & 11.7 \\
Total & 68 & 100.0 \\
\hline
\end{tabular}

Table 3. Monthly Distribution of Cases.

\begin{tabular}{lll}
\hline Month & Frequency & Percentage \\
\hline January & 8 & 11.8 \\
February & 9 & 13.2 \\
March & 5 & 7.4 \\
April & 2 & 2.9 \\
May & 2 & 2.9 \\
June & 5 & 7.4 \\
July & 4 & 5.9 \\
August & 7 & 10.3 \\
September & 8 & 11.8 \\
October & 7 & 10.3 \\
November & 5 & 7.4 \\
December & 6 & 8.8 \\
\hline
\end{tabular}

Table 3 above demonstrates that the months of January and February had the greatest number of patients with pneumonia while a second peak occurred between the months of August 
and October.

Table 4. Outcome of admission.

\begin{tabular}{lll}
\hline Outcome & No of patients & Percentage \\
\hline Discharged home & 63 & 92.6 \\
Dead & 3 & 4.4 \\
DAMA & 2 & 2.9 \\
Total & 68 & 100.0 \\
\hline
\end{tabular}

DAMA: Discharged against medical advice.

Majority 63 (92.6\%) of the patients were discharged home while $3(4.4 \%)$ suffered mortality (Table 4$)$.

\section{Discussion}

Our study revealed a prevalence of childhood pneumonia of $16.8 \%$. This is higher than the values reported in developed countries such as $0.14 \%$ in the UK [10] and 15.7 22.5/100,000 admissions in the US [11] but lower than the $29.9 \%$ in Pakistan [17] and 27.68\% reported in Makurdi North central state [14] and 23.5\% reported in Ilesha South west of Nigeria [15]. Our value is much higher than reports from developed countries because of the higher socioeconomic status of the later, together with availability of better sanitation and health preventive measures. Again, the state-of-the-art health management facilities in developed countries [18] make the prevalence and mortality from illnesses lower, childhood pneumonia inclusive.

The result from Pakistan is higher than ours notably because the country is located on a higher altitude with its attendant coldness of temperature which predisposes to higher prevalence of pneumonia [17]. Makurdi and Ilesha reported higher results than ours most probably because pneumococcal conjugate vaccine application had not been commenced in Nigeria by the years 2011 to 2013, when the patients in those studies were attended to while. Our patients were admitted in 2016 after the commencement of the vaccine in 2014 [19] thereby curbing the prevalence reported in our study. Also, the Makurdi study [14] was conducted on children aged less than five (in whom there is a higher prevalence of pneumonia than in the general childhood population), while ours was conducted on all the children that were attended to during the study period.

Our study also revealed a higher prevalence of pneumonia in males than in females. Pneumonia occurring more in male children than in females has been universally reported $[10,11$, 14, 15]. The reason for such occurrence has been attributed partly to preference for male children in the health care seeking behavior of some care givers [17]. Also, certain infectious diseases including pneumonia have been noted to occur more frequently in males [20]. Male peripheral respiratory tract has been noted to be smaller than female's in early life resulting in increased susceptibility to pneumonia [20].

Our result showed that $91.2 \%$ of the cases occurred in children less than five years while a large majority $61.8 \%$ occurred in infants. This is in keeping with the findings universally reported previously $[14,15]$. This could be explained by the fact that early childhood is a period during which active immunity begins to develop from about $6-12$ months of life (with the waning of maternally derived immunity) predisposing the child to infections including pneumonia [21]. The prevalence starts to wane with increasing immunity becoming minimal with the development of adequate immunity by about the fifth year of life [21]. Also, the developing child becomes more able to avoid predisposing factors such as cold, indoor pollution with greater mental and physical maturity and activity after the age of five [22] decreasing the tendency to develop pneumonia significantly.

Our result showed that the greatest number of cases were recorded in January and February, with a second peak between August and October. These correspond to periods in the dry and rainy seasons respectively [23]. Similar reports of pneumonia occurring more in the early, dry months (harmattan season) [26] of the year have also been recorded in Taiwan [24] Kenya [25], Kano in Nigeria [26] but contrasts with South Africa where the peak occurred in winter months [27]. The peak of January to February recorded in our study could be explained by these being months of dry, dusty and windy harmattan season with so much outdoor pollution, environmental cold and drying of the respiratory tract (resulting in defective cilia function) leading to peak occurrence of pneumonia [26].

The peak in August to October could be explained by this being the rainy season which is often associated with cold, and greater likelihood of indoor pollution from indoor cooking with stove, predisposing children to increased likelihood of occurrence of pneumonia [28].

This index study showed a case fatality of $4.4 \%$. This is higher than the 1.8/10000 documented for high income countries in 2012 [28] However, higher reports of $8.8 \%$ and $10.8 \%$ case fatality rates were documented in Makurdi [14] north-central and Ebonyi [29] southeastern states of Nigeria respectively. The case fatalities for developed countries could be lower for reasons of availability of excellent sanitary standards, effective preventive measures [18] and state-ofthe-art health management facilities in those countries in contrast to the situation in the developing nations to which our country belongs. Case fatalities could have been worse in Markurdi and Ebonyi probably because their studies were conducted on patients managed from 2011 to 2013 [14] and 2005 to 2010 [29] respectively when pneumococcal conjugate vaccine had not been commenced in Nigeria. Ours was conducted on patients managed in 2016 after the commencement of the vaccine in 2014 [19]. This may have led to lower case fatality recorded in our study.

\section{Conclusion}

The study reveals a high prevalence of childhood pneumonia occurring in children less than five and particularly in infants, with peaks in the months of January/February and August to October. Protection of young children particularly infants from the risk factors of 
pneumonia cannot be over-emphasized.

General protective measures to institute include: regular administration of pneumococcal conjugate vaccine, protection from indoor and outdoor pollution, avoidance of overcrowding, ensuring indoor and environmental sanitation especially in the months of January/February and August to October.

Also, there should be regular advocacy for provision of adequately equipped healthcare facilities in close proximity to citizens' place of habitation by governments at the federal, state and local levels.

\section{Authorship Contributions}

$\mathrm{O} \mathrm{C} \mathrm{N}$ conceived and designed the manuscript, helped in acquisition of data, analysis and interpretation of data, and also wrote the manuscript.

$\mathrm{O} \mathrm{N}$ C contributed in the design of the manuscript, interpretation of the analyzed data, writing and revision of the manuscript, and gave final approval of the version to be published.

\section{Conflict of Interest}

The authors declare that they have no competing interests.

\section{Acknowledgements}

Our gratitude goes to the nursing staff of Paediatrics Department for providing the admission registers, the staff of the Medical Records Department for pulling out the case files and to the registrar who helped with the extraction of the data.

\section{References}

[1] Rudan I, Boschi-Pinto C, Biloglav Z, Mulholland K, Campbell H. Epidemiology and etiology of childhood pneumonia. Bull World Health Organ. 2008; 86 (5): 408416.

[2] Black RE, Cousens S, Johnson HL, Lawn JE, Rudan I, Bassani DG et al. Global, regional, and national causes of child mortality in 2008: a systematic analysis. Lancet. 2010; 375 (9730): 1969-1987.

[3] UNICEF: Nigeria contributes highest number to global pneumonia child deaths. https//www.Unicef.org Nov 2019 [Accesses 20 April 2021].

[4] Ghafoor A, Nomani NK, Ishaq Z, Zaidi SZ, Anwar F, Burney MI et al. Diagnoses of acute lower respiratory tract infections in children in Rawalpindi and Islamabad, Pakistan. Rev Infect Dis. 1990; 12: S 907-14 pmid: 2270413.

[5] Epidemiology and etiology of childhood pneumonia. Bulletin of the World Health Organization https://www.who.int/bulletin/volumes/86/5/07-048769/en/ [Accessed 20 April 2021].
[6] Owayed AF, Campbell DM, Wang E L. Underlying Causes of Recurrent Pneumonia in Children. Arch Pediatr Adolesc Med. 2000; 154 (2): 190-194. doi: 10.1001/archpedi.154.2.190.

[7] Beard LJ, Maxwell GM, Thong YH. Immunocompetence of children with frequent respiratory infections. Arch Dis Child. 1981; 56: 101-105. Google Scholar Crossre.

[8] WHO: Pneumonia https://www.who.int/news-room/factsheets/detail/pneumonia. August 2019. [Accessed 20 April 2021].

[9] Wootton D, Feldman C. The diagnosis of pneumonia requires a chest radiograph (x-ray) - yes, no or sometimes? Pneumonia. 2014. 5: 1-7. https://doi.org/10.15172/pneu.2014.5/464.

[10] Katz SE, Williams DJ. Pediatric Community-Acquired Pneumonia in the United States Changing Epidemiology, Diagnostic and Therapeutic Challenges, and Areas for Future Research. Infect Dis Clin North Am. 2018; 32 (1): 47-63.

[11] Clark JE, Hammal D, Hampton F, Spencer D, Parker L. Epidemiology of community-acquired pneumonia in children seen in hospital. Epidemiol Infect. 2007; 135 (2): 262-269. doi: $10.1017 / \mathrm{S} 0950268806006741$.

[12] Osei FA, Mensah KA, Ansong D, Agyei-Baffour P, Owusu S, Mensah NK Prevalence of pneumonia and risk factors of pneumonia mortality among children under five years. African Journal of Current Medical Research. 2018; 2 (2): https://doi.org/10.31191/afrijcmr.v2i2.28. [Accessed 20 April 2021].

[13] DeAntonio R, Yarzabal J, Cruz JP, Schmidt JE, Kleijnen J. Epidemiology of community-acquired pneumonia and implications for vaccination of children living in developing and newly industrialized countries: A systematic literature review. Human Vaccines \& Immunotherapeutics. 2016; 12 (9): 2422-2440, DOI: 10.1080/21645515.2016.1174356.

[14] Amai IU, Aguoru CU, Amai D C. Prevalence of Pneumonia in Children under Five Years Old Attending the Federal Medical Centre, Makurdi, Nigeria. Human Journals. 2018; 10 (2): 142151 .

[15] BP Kuti, AO Oyelam. Childhood community-acquired pneumonia at the Wesley guild hospital, Illesa: Prevalence, pattern, and outcome determinants. Nigerian Journal of Health Sciences: 2015; 15 (2): 98-104.

[16] UNICEF: Child survival and the SDGs. September 2019 https://data.unicef.org/topic/child-survival/child-survival-sdgs [Accessed 20 April 2021].

[17] Chan AJ, Omer SB, Hu ssain H, Chaudry S. High incidence of childhood pneumonia at high altitudes in Pakistan: A longitudinal cohort study. Bulletin of the World Health Organisation. 87 (3): 193-9.

[18] Gray S, Pilkington P, Pencheon D. Jewell T. Public health in the UK: success or failure? Journal of the Royal Society of Medicine. 2006; 99 (3): 107-111.

[19] WHO: Nigeria Introduces New Vaccine - PCV10 https://www.afro.who.int/news/nigeria-introduces-newvaccine-pcv-10Dec 2014. [Accessed 20 April 2021].

[20] Falagas ME, Mourtzoukou EG, Vardakas KZ. Sex differences in the incidence and severity of respiratory tract infections. Respiratory Medicine. 2007; 191 (9): 1845-1863. 
[21] Georgountzou A, Papadopoulos N. Postnatal Innate Immune Development: From Birth to Adulthood. Front Immunol. 2017; 8: 957. doi: 10.3389/fimmu.2017.00957.

[22] Child development at 5-6 years: https://raisingchildren.net.au/schoolage/development/development-tracker/5-6-years [Accessed 20 April 2021].

[23] Rainy Season in Nigeria https://hintng.com/rainy-season-innigeria. September 2018 [Accessed 20 April 2021].

[24] Hsiu-Chen Lin, Ching-Chun Lin, Chin-Shyan Chen, HerngChing Lin Seasonality of pneumonia admissions and its association with climate: An eight-year nationwide population-based study Chronobiology International 2009; 26 (8): 1647-59.

[25] Myer LD, Nicol MP, Zar HZ. The epidemiology of hospitalized pneumonia in rural Kenya: the potential of surveillance data in setting public health priorities. International Journal of Infectious Diseases. 2007; 11 (6): 536-543.
[26] Iliyasu G, Mohammad FD, Habib AG. Community Acquired Pneumococcal Pneumonia in Northwestern Nigeria: Epidemiology, Antimicrobial Resistance and Outcome. Afr $J$ Infect Dis. 2017; 12 (1): 15-19.

[27] Myer LD, Nicol MP, Zar HJ.. Incidence and severity of childhood pneumonia in the first year of life in a South African birth cohort: the Drakenstein Child Health Study. The Lancet. Global Health. 01 Feb 2015; 3 (2): e95-e103. DOI: 10.1016/s2214-109x(14)70360-2 [Accessed 20 April 2021].

[28] Sunyataningkamto S, Iskandar Z, Alan RT, Budiman I, Ahmad $\mathrm{S}$, Wibowo T. The role of indoor air pollution and other factors in the incidence of pneumonia in under-five children. Paediatrica Indonesiana. 10 Oct. 2016; 44 (1): 25-29. Available from: https://paediatricaindonesiana.org/index.php/paediatricaindonesiana/article/view/729 [Accessed 20 April 2021].

[29] Ezeonu CT, Uneke CJ, Ojukwu JO, Anyanwu OU, Okike CO, Ezeanosike $\mathrm{OB}$, et al. The pattern of pediatric respiratory illnesses admitted in Ebonyi State University Teaching Hospital South-East Nigeria. Ann Med Health Sci Res. 2015; 5: 65-70. 